\title{
Systematic Review of the Surgery-first Approach in Orthognathic Surgery
}

\author{
Chiung Shing Huang ${ }^{1,2}$, Sam Sheng-Pin Hsu³, Yu-Ray Chen ${ }^{2,4}$
}

\begin{abstract}
The surgery-first approach in orthognathic surgery has recently created a broader interest in completely eliminating time-consuming preoperative orthodontic treatment. Available evidence on the surgery-first approach should be appraised to support its use in orthognathic surgery. A MEDLINE search using the keywords "surgery first" and "orthognathic surgery" was conducted to select studies using the surgery-first approach. We also manually searched the reference list of the selected keywords to include articles not selected by the MEDLINE search. The search identified 18 articles related to the surgery-first approach. There was no randomized controlled clinical trial. Four papers were excluded as the content was only personal opinion or basic scientific research. Three studies were retrospective cohort studies in nature. The other 11 studies

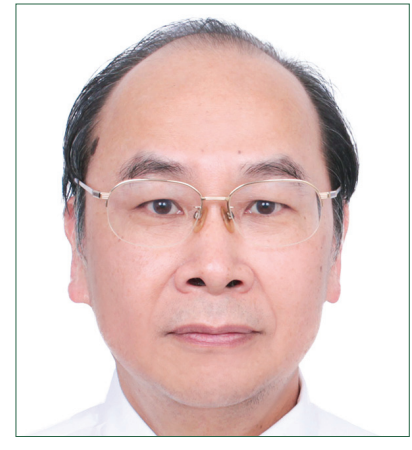

Prof. Chiung Shing Huang were case reports. For skeletal Class III surgical correction, the final long-term outcomes for maxillofacial and dental relationship were not significantly different between the surgery-first approach and the orthodontics-first approach in transverse (e.g., intercanine or intermolar width) dimension, vertical (e.g., anterior open bite, lower anterior facial height) dimension, and sagittal (e.g., anteriorposterior position of pogonion and lower incisors) dimension. Total treatment duration was substantially shorter in cases of surgery-first approach use. In conclusion, most published studies related to the surgery-first approach were mainly on orthognathic correction of skeletal Class III malocclusion. Both the surgery-first approach and orthodontics-first approach had similar long-term outcomes in dentofacial relationship. However, the surgery-first approach had shorter treatment time.
\end{abstract}

(Biomed J 2014;37:184-190)

\section{Key words: mandibular prognathism, orthognathic surgery, surgery-first approach}

$\mathrm{I}_{\mathrm{i}}^{\mathrm{n}}$ n 1849, Hullihen first reported the orthognathic correction of mandibular elongation. ${ }^{[1]}$ Since then, numerous surgical techniques have been used for the dissection of the mandibular body or ascending ramus to correct mandibular prognathism. In 1957, Trauner and Obwegeser ${ }^{[2]}$ introduced sagittal splitting ramus osteotomy, which marked the beginning of the modern era of orthognathic surgery. This intraoral approach could move the mandible in three dimensions according to a designated surgical plan, keeping the condyle in the glenoid fossa, and, most importantly, maintaining sufficient bone contact area to allow primary bone healing after orthognathic surgery. After introducing osteotomy in the mandible, Obwegeser was also the first to develop LeFort I osteotomy to move the maxilla in all three dimensions, reporting a large series of maxillary osteotomy cases in $1969 .{ }^{[3]}$ In the 1960 s, surgeons rarely depended on orthodontic treatment to move the teeth prior to surgery. They performed orthognathic surgery either before orthodontic treatment or after the removal of orthodontic appliances. During those years, surgeons, thus, commonly used

From the ${ }^{1}$ Faculty of Dentistry, Chang Gung Craniofacial Research Center, Chang Gung Memorial Hospital at Taipei, Chang Gung University College of Medicine, Taoyuan, Taiwan; ${ }^{2}$ Graduate Institute of Craniofacial and Dental Science, College of Medicine, Chang Gung University, Taoyuan, Taiwan; ${ }^{3}$ Department of Craniofacial Orthodontics, Faculty of Dentistry, Chang Gung Craniofacial Research Center, Chang Gung Memorial Hospital at Taipei, Chang Gung University College of Medicine, Taoyuan, Taiwan; ${ }^{4}$ Department of Plastic Surgery, Chang Gung Craniofacial Research Center, Chang Gung Memorial Hospital at Taipei, Chang Gung University College of Medicine, Taoyuan, Taiwan

Received: Sep. 09, 2013; Accepted: Jan. 28, 2014

Correspondence to: Prof. Chiung Shing Huang, Faculty of Dentistry, Chang Gung Craniofacial Research Center, Chang Gung Memorial Hospital at Taipei. 199 Dunhua N. Rd., Taipei 105, Taiwan (ROC). Tel: 886-27135211 ext. 3528; Fax: 886-2-27135211-3300; E-mail: cshuang@cgmh.org.tw

DOI: $10.4103 / 2319-4170.126863$ 
a surgery-first approach for orthognathic surgery. In 1963, Poulton et al..$^{[4]}$ reported five cases of mandibular prognathism successfully treated with bilateral vertical osteotomy without any orthodontic treatment. However, it was soon recognized that the amount of mandibular setback was limited by the overjet between the upper and lower anterior incisors. To increase the amount of surgical setback to correct mandibular prognathism, orthodontic treatment was needed to arrange the malaligned teeth in the best possible position in the individual jaws prior to surgery. ${ }^{[5]}$ Worms et al. ${ }^{[6]}$ expanded this "orthodontics-first" concept to all orthognathic cases, including mandibular prognathism, mandibular retrognathism, and vertical skeletal discrepancy with anterior open bite or deep bite, and emphasized that optimal surgical repositioning of the jaw is only possible following the removal of all dental compensation prior to surgery. Comprehensive orthodontic treatment to align dental occlusion, incisor decompensation, tooth rotation, and arch coordination should, therefore, be conducted 8-18 months before orthognathic surgery. ${ }^{[7-12]}$ The orthodontics-first approach became the standard procedure for orthognathic surgical treatment after the $1970 \mathrm{~s},{ }^{[13-15]}$ with most orthognathic teams implementing this approach. ${ }^{[16]}$ However, in recent years, Dr. William Bell commented that orthognathic surgery was too complicated, too invasive, too time-consuming, too expensive, and too unpredictable, ${ }^{[17]}$ establishing the Symposium of "Paradigm Shifts in Orthognathic Surgery" in 2007 with his colleagues from the University of Texas Southwestern Medical Center. Their aim was to facilitate the provision of orthognathic surgery in more efficient, affordable, predictable, and convenient ways, thus improving the quality of care. In addition to introducing clinical applications of advanced three-dimensional medical imaging and office-based surgery, the 2011 symposium presented the surgery-first approach and created broader interest in the complete elimination of time-consuming preoperative orthodontic treatment. ${ }^{[18,19]}$ The present systematic review aims to appraise the currently available evidence on the surgery-first approach and support its use in orthognathic surgery.

\section{Methods}

A MEDLINE search (Entrez PubMed, www.ncbi.nim. nih.gov) was conducted using the subject headings "surgery first" and "orthognathic surgery" and 258 articles were obtained. Abstracts of these articles were reviewed to select the studies that used a surgery-first approach. The reference list of each selected article was examined to include articles not retrieved by the MEDLINE search. The inclusion criteria were 1) human study and 2) orthognathic surgery using a surgery-first approach or its equivalent. Personal opinion was excluded.

\section{Results}

The MEDLINE search and review of reference lists identified 18 articles relating to the surgery-first approach. Four papers were excluded: Three included only personal opinion $^{[20-22]}$ and one conducted basic scientific research on accelerated factors related to postoperative rapid orthodontic tooth movement. ${ }^{[18]}$ Table 1 lists the 14 analyzed papers. Most (11 out of 14, 78.6\%) were case reports; four reported only one case. ${ }^{[23-26]}$ The first four papers, published prior to 1988, were case reports on the surgical-orthodontic correction of mandibular prognathism and long face syndrome with anterior open bite, and mentioned the concept of the surgery-first approach in their discussion sections. Only three studies had performed retrospective cohort analyses to compare the differences between the orthodontics-first and the surgery-first approaches. ${ }^{[27-29]}$ The search results indicated that a prospective cohort study or randomized controlled trial on the surgery-first approach has not yet been conducted.

\section{Treatment time for preoperative orthodontic treatment}

Most articles recommended that orthodontic appliances should be fitted prior to surgery, even when using a surgery-first approach. Studies reported bonding the orthodontic brackets immediately before, ${ }^{[24,25]} 1$ week before, ${ }^{[19,23,26]} 1$ month before ${ }^{[27-29]}$ or 1-2 months before ${ }^{[30]}$ surgery. Only one of the papers reported the total elimination of preoperative orthodontic treatment and the fitting of orthodontic brackets 10-14 days after surgery. ${ }^{[31]}$ Studies described that active orthodontic force can be applied before ${ }^{[26-29]}$ or shortly after ${ }^{[19,23-25,30]}$ surgery. Preoperative orthodontic preparation can, therefore, be started immediately before or approximately 1-2 months before surgery. Occasionally, it might be completely eliminated.

\section{Treatment time for postoperative orthodontic treatment}

The shortest reported treatment time for postoperative orthodontic treatment was 4 months for correction of a skeletal Class III malocclusion with anterior open bite and dental crowding. ${ }^{[26]}$ Most studies described completing postoperative orthodontic treatment within approximately 1 year ${ }^{[25,27,28,30]}$ or in 6-9 months. ${ }^{[23,24,31]}$ Treatment time was approximately 6-12 months shorter using a surgery-first approach compared with using a conventional orthodontics-first approach. Only one study described similar treatment times (approximately 1.5 years) for both approaches. ${ }^{[29]}$

\section{Stability of surgical-orthodontic treatment}

Three papers described the stability of craniofacial structures 1 year or more after orthognathic surgery. ${ }^{[27-29]}$ 
Table 1: Summary of studies using surgery-first approach in orthognathic surgery and their outcomes

\begin{tabular}{|c|c|c|c|c|c|c|c|}
\hline Authors, year & $\begin{array}{l}\text { Study design } \\
\text { Sample }(n)\end{array}$ & $\begin{array}{l}\text { Type of } \\
\text { malocclusion }\end{array}$ & $\begin{array}{l}\text { Mean age in } \\
\text { years (range) }\end{array}$ & $\begin{array}{l}\text { Surgical } \\
\text { method }\end{array}$ & $\begin{array}{l}\text { Preoperative } \\
\text { orthodontic treatment }\end{array}$ & $\begin{array}{c}\text { Total } \\
\text { treatment time }\end{array}$ & Authors' conclusion \\
\hline $\begin{array}{l}\text { Poulton et al., } \\
1963^{[4]}\end{array}$ & $\begin{array}{l}\text { Case } \\
\text { series (5) }\end{array}$ & $\begin{array}{l}\text { Mandibular } \\
\text { prognathism }\end{array}$ & $22(16-27)$ & VRO & n.a. & n.a. & $\begin{array}{l}\text { Stable results achieved } \\
\text { without preoperative } \\
\text { orthodontic treatment }\end{array}$ \\
\hline $\begin{array}{l}\text { Bell et al., } \\
1973^{[5]}\end{array}$ & $\begin{array}{l}\text { Case } \\
\text { series (6) }\end{array}$ & $\begin{array}{l}\text { Mandibular } \\
\text { prognathism }\end{array}$ & $22(14-49)$ & VRO & 15.8 months & 22.1 months & $\begin{array}{l}\text { Minimal orthodontic treatment } \\
\text { before the surgery proposed }\end{array}$ \\
\hline $\begin{array}{l}\text { Epker and } \\
\text { Fish, 1977 }\end{array}$ & $\begin{array}{l}\text { Case } \\
\text { series (2) }\end{array}$ & $\begin{array}{l}\text { Anterior open } \\
\text { bite }\end{array}$ & $14.5(12-17)$ & $\mathrm{LF}+\mathrm{GN}$ & 4,12 months & 12,28 months & $\begin{array}{l}\text { Surgery-first approach } \\
\text { better than orthodontics-first } \\
\text { approach in some cases }\end{array}$ \\
\hline $\begin{array}{l}\text { Behrman } \\
\text { et al., } 1988^{[22]}\end{array}$ & $\begin{array}{l}\text { Case } \\
\text { series (8) }\end{array}$ & $\begin{array}{l}\text { Dentofacial } \\
\text { deformity }\end{array}$ & n.a. & $\mathrm{BSSO}+\mathrm{MX}$ & n.a. & n.a. & $\begin{array}{l}\text { To do surgery first and } \\
\text { orthodontics second }\end{array}$ \\
\hline $\begin{array}{l}\text { Nagasaka } \\
\text { et al., 2009 }\end{array}$ & Case (1) & $\begin{array}{l}\text { Skeletal } \\
\text { Class III }\end{array}$ & 17 & BSSO & Just before surgery & 12 months & $\begin{array}{l}\text { Greatly reduced treatment } \\
\text { time }\end{array}$ \\
\hline $\begin{array}{l}\text { Sugawara } \\
\text { et al., } 2010^{[24]}\end{array}$ & Case (1) & $\begin{array}{l}\text { Skeletal } \\
\text { Class II }\end{array}$ & 44 & BSSO & Just before surgery & 9 months & $\begin{array}{l}\text { Effectively corrected skeletal } \\
\text { Class II malocclusion }\end{array}$ \\
\hline $\begin{array}{l}\text { Villegas } \\
\text { et al., 2010 }\end{array}$ & Case (1) & $\begin{array}{l}\text { Facial dental } \\
\text { asymmetry }\end{array}$ & 20 & BSSO & 1 week & 7 months & $\begin{array}{l}\text { Facial asymmetry corrected by } \\
\text { surgery-first approach }\end{array}$ \\
\hline $\begin{array}{l}\text { Yu et al., } \\
2010^{[26]}\end{array}$ & Case (1) & $\begin{array}{l}\text { Mandibular } \\
\text { prognathism }\end{array}$ & 19 & $\mathrm{LF}+\mathrm{BSSO}+\mathrm{GN}$ & 1 week & 4 months & $\begin{array}{l}\text { Total treatment within } 4 \\
\text { months }\end{array}$ \\
\hline $\begin{array}{l}\text { Wang et al., } \\
2010^{[27]}\end{array}$ & $\begin{array}{l}\text { Cohort } \\
\text { study (36) }\end{array}$ & $\begin{array}{l}\text { Skeletal } \\
\text { Class III }\end{array}$ & 22.3 & $\mathrm{LF}+\mathrm{BSSO}$ & 1 month & 12 months & $\begin{array}{l}\text { Maxillary expansion not } \\
\text { needed before the surgery }\end{array}$ \\
\hline $\begin{array}{l}\text { Liao et al., } \\
2010^{[28]}\end{array}$ & $\begin{array}{l}\text { Cohort } \\
\text { study (104) }\end{array}$ & $\begin{array}{l}\text { Skeletal } \\
\text { Class III+open } \\
\text { bite }\end{array}$ & $(21-23)$ & $\mathrm{LF}+\mathrm{BSSO}$ & 1 month & 342 days & $\begin{array}{l}\text { Shorter treatment time for } \\
\text { surgery-first approach, no } \\
\text { difference in stability }\end{array}$ \\
\hline $\begin{array}{l}\text { Kao et al., } \\
2010^{[29]}\end{array}$ & $\begin{array}{l}\text { Cohort } \\
\text { study (53) }\end{array}$ & $\begin{array}{l}\text { Skeletal } \\
\text { Class III }\end{array}$ & $(22-24.6)$ & $\mathrm{LF}+\mathrm{BSSO}$ & 21 days & 534.6 days & $\begin{array}{l}\text { No difference in skeletal } \\
\text { correction and postsurgical } \\
\text { relapse }\end{array}$ \\
\hline $\begin{array}{l}\text { Baek et al., } \\
2010^{[30]}\end{array}$ & $\begin{array}{l}\text { Case } \\
\text { series (11) }\end{array}$ & $\begin{array}{l}\text { Skeletal } \\
\text { Class III }\end{array}$ & 22.95 & $\mathrm{LF}+\mathrm{BSSO}$ & $1-2$ months & 12.18 months & $\begin{array}{l}\text { Accurate prediction of } \\
\text { postoperative orthodontic } \\
\text { treatment needed }\end{array}$ \\
\hline $\begin{array}{l}\text { Liou et al., } \\
2011^{[18]}\end{array}$ & $\begin{array}{l}\text { Case } \\
\text { series (5) }\end{array}$ & $\begin{array}{l}\text { Skeletal } \\
\text { Class III }\end{array}$ & (Adult) & $\mathrm{LF}+\mathrm{BSSO}$ & 1 month & $1-1.5$ years & $\begin{array}{l}\text { Treatable "transitional" } \\
\text { occlusion created after the } \\
\text { surgery }\end{array}$ \\
\hline $\begin{array}{l}\text { Hernandez, } \\
2011^{[31]}\end{array}$ & $\begin{array}{l}\text { Case } \\
\text { series (2) }\end{array}$ & $\begin{array}{l}\text { Skeletal } \\
\text { Class III }\end{array}$ & $20-23$ & $\mathrm{LF}+\mathrm{BSSO}$ & None to 1 month & 6.5-8.8 months & $\begin{array}{l}\text { Precise diagnosis and detailed } \\
\text { treatment plan needed for } \\
\text { surgery-first approach }\end{array}$ \\
\hline
\end{tabular}

Abbreviations: BSSO: Bilateral sagittal split osteotomy of the mandible; GN: Genioplasty; LF: LeFort I osteotomy; MX: Maxillary osteotomy; n.a: Not available; VRO: Vertical ramus oblique osteotomy of the mandible

For transverse problems, Wang et al..$^{[27]}$ investigated 36 adult patients with skeletal Class III malocclusion, who underwent LeFort I osteotomy and/or bilateral sagittal splitting osteotomy of the mandible. The same experienced surgeon performed all operations. The patient groups differed only in receiving the preoperative orthodontic treatment $(6$ months on average). Preoperative orthodontic treatment might involve the leveling and alignment of dental arches and elimination of major occlusal interferences. For maxillary canine inclination, the preoperative orthodontic treatment was successful in expanding intercanine width. However, 1 year after surgery, there were no differences between the orthodontics-first group and the surgery-first group in inclinations of the maxillary canine, mandibular canine, maxillary molar, and mandibular molar. The authors concluded that the final outcomes of the transverse dental changes were similar irrespective of receiving preoperative orthodontic treatment or not.
For vertical problems, Liao et al. ${ }^{[28]}$ evaluated skeletal Class III open bite patients using a surgery-first or orthodontics-first approach at four different time points (before treatment, 1 month before surgery, 1 week after surgery, and at orthodontic debonding). During 2002-2005, 33 consecutively operated patients received LeFort I posterior impaction osteotomy and bilateral sagittal splitting osteotomy to correct skeletal Class III open bite. Of these 33 patients, 13 received an orthodontics-first approach and 20 a surgery-first approach. The surgery-first approach was associated with a significantly shorter treatment time than the orthodontics-first approach (342 days vs. 512 days). Both groups displayed similar maxillary stability in the horizontal and vertical directions and similar mandibular stability in the horizontal direction. The only detectable difference was increased upward mandibular movement following surgery in the surgery-first approach group compared with the 
orthodontics-first approach group. This upward mandibular movement could help to prevent relapse of the anterior open bite. For surgical orthodontic correction of skeletal Class III open bite, the orthodontics-first approach does not offer greater benefits in the way of facial esthetics, dental occlusion, or treatment stability than the surgery-first approach.

For sagittal problems, Ko et al. ${ }^{[29]}$ investigated 53 skeletal Class III patients receiving LeFort I osteotomy and bilateral sagittal splitting osteotomy of mandible between 2003 and 2007. The same experienced surgeon performed all operations. Of these 53 patients, 18 underwent a surgery-first approach and 35 an orthodontics-first approach. The final outcomes, in the way of skeletal correction and postsurgical relapse, displayed no differences between the two approaches. Upon the completion of treatment, the preoperative orthodontic work on the incisor proclination had returned to the original incisor inclination. Lengthy preoperative orthodontic preparation for dental decompensation is, therefore, not necessary prior to the surgical correction of skeletal Class III malocclusion.

\section{Discussion}

During the last 40 years, investigators have placed sporadic emphasis on the surgery-first approach in orthognathic surgery. In 1977, when the orthodontics-first approach showed popularity, Epker and Fish suggested that for the surgical repositioning of skeletal and/or dento-osseous segments, the surgical procedure should be performed prior to the orthodontic treatment. ${ }^{[32]}$ This would ensure esthetically pleasing results and safely and easily accomplish tooth movement. The authors described several advantages offered by the surgery-first approach: (1) Improvement in patient's facial esthetics and dental function early in treatment, rather than following a period of possible years, (2) improvement in patient's swallowing and speech functions after surgery, (3) the proceeding of orthodontic tooth movement at a much faster pace following surgery, thus reducing the overall treatment time, (4) improved cooperation of the patient during orthodontic treatment, (5) easier orthodontic tooth movement following restoration of the normal functional and anatomic relationships of the bony skeleton and surrounding soft tissues, and (6) stability of results equal to, or in some cases superior to, those achieved using the more traditional orthodontics-first approach. Epker and Fish described postoperatively accelerated orthodontic tooth movement in patients receiving orthognathic surgery in 1977; this was almost 23 years before the reporting of the regional acceleratory phenomenon (RAP) in orthodontic treatment by Wilcko et al. ${ }^{[33]}$

The surgery-first approach gained further support from Lee in $1994 .{ }^{[21]} \mathrm{He}$ emphasized the early correction of skeletal and soft tissue problems, stating that orthodontic treatment is easier to perform following the achievement of a relatively normal skeletal and soft tissue environment after orthognathic surgery. The described clinical benefits of a surgery-first approach included shorter overall treatment time, more biologically favorable tooth movement, more predictable occlusal results, more rapid tooth movement achieved postoperatively, improved coordination of the upper and lower dental arches, and earlier musculature adaption to maintain the altered arch relationship. Although this article provided no solid clinical data to support the claimed advantages, the described clinical phenomena remain valid presently.

The group of Sugawara and Nanda published a series of case reports using a surgery-first approach to correct skeletal Class III ${ }^{[25]}$ and skeletal Class II $^{[24]}$ malocclusion and dentofacial asymmetry. ${ }^{[23]}$ The results demonstrated entirely acceptable facial esthetics and dental occlusion, with total treatment time of less than 12 months. Their use of the surgery-first approach attracted attention to the paradigm shift from the traditional orthodontics-first approach. The authors documented that skeletal problems could be immediately corrected using orthognathic surgery without performing any preoperative orthodontic treatment. In their three case reports, orthognathic surgery was performed on the mandible only. A Class III malocclusion becomes Class II immediately after mandibular setback, and a Class II malocclusion becomes Class III immediately after mandibular advancement. The Skeletal Anchorage System (SAS) must then be used to correct the intentionally created Class III or Class II malocclusion by moving posterior teeth to achieve a final Class I relationship. ${ }^{[34,35]}$ However, the most common combination of variables for Class III malocclusion was a retrusive maxilla, protrusive mandible, protrusive maxillary incisors, retrusive mandibular incisors, and a long lower facial height. ${ }^{[36]}$ Previous reports on surgical correction of mandibular prognathism described the use of an isolated mandibular setback in fewer than $10 \%$ of patients, in favor of maxillary advancement or bimaxillary orthognathic surgery. ${ }^{[17,37]}$ Similarly, the most common characteristics for Class II malocclusion were retrusive mandible $(60 \%)$, protrusive maxilla (55.8\%), and a reduced vertical skeletal jaw relationship. In surgical correction of mandibular retrognathism, bimaxillary orthognathic surgery should be considered instead of mandibular advancement. ${ }^{[38]}$ Therefore, orthognathic surgery to correct skeletal Class III or Class II malocclusion should not be limited to using mandibular osteotomy only. Mandibular osteotomy alone creates a more difficult occlusal problem for the orthodontist to treat following surgery.

In 2010, Baek et al. ${ }^{[30]}$ emphasized that the surgery-first approach requires accurate prediction of the postoperative orthodontic treatment for dental alignment, incisor decompensation, arch coordination, and occlusal settling 
at the very beginning of a preoperative treatment plan. Their study reported 11 cases of skeletal Class III malocclusion treated using a surgery-first approach and the observations included increased patient cooperation, efficient and effective decompensation, and shortened treatment time compared to using an orthodontics-first approach. They applied two-jaw surgery using LeFort I osteotomy to impact the posterior maxilla and bilateral sagittal splitting osteotomy for mandibular setback. However, the authors mentioned some disadvantages of using a surgery-first approach, such as high bonding failure, difficulty in bending the surgical wire to fit into unleveled dentition, the requirement for more surgical movement to compensate for postoperative orthodontic movement, impacted lower third molars, and postsurgical occlusal instability. Surgical orthodontic teams applying a surgery-first approach could encounter all these problems. These should, thus, be resolved prior to its application.

Hernaande-Alfaro et al. ${ }^{[31]}$ reported two skeletal Class III anterior open bite cases receiving bimaxillary orthognathic surgery using a surgery-first approach. The total treatment time was 264 days ( 8.8 months) for patient 1 and 195 days ( 6.5 months) for patient 2 . Both patients were satisfied with the results of rapid facial changes and shortened treatment time. The authors emphasized that providing precise diagnosis, detailed treatment planning, and skillful orthodontic treatment is more demanding using a surgery-first approach than a traditional orthodontics-first approach.

To provide more evidence to support the surgery-first approach, the researchers have conducted a series of investigations to compare transverse, vertical, and sagittal changes in surgery-first approach group with those in orthodontics-first approach group.

Grubb and Evans described that using an orthodontics-first approach for skeletal Class III malocclusion, ${ }^{[12]}$ any transverse maxillary width discrepancy should be corrected by preoperative orthodontic expansion, or by surgically assisted rapid palatal expansion, before or during orthognathic correction of Class III sagittal discrepancy. Maxillary expansion should be performed before orthognathic surgery. ${ }^{[12-14]}$ However, even without preoperative maxillary expansion, the maxillary molar width should be sufficient to allow coordination with the mandibular molars after upper and lower dental casts are brought into a Class I position. Irrespective of the approach that was taken, the molar width decreased continuously after orthognathic surgery. ${ }^{[27]}$ Eventually, both maxillary and mandibular molar widths did not differ significantly between the surgery-first and orthodontics-first groups 1 year after the operation. Why should the molar width be increased prior to the operation, as proposed by the orthodontics-first approach?

Preoperative orthodontic correction of long face syn- drome with anterior open bite might involve leveling of the curve of Spee to worsen the anterior open bite before surgery. This might create the need for surgical impaction of the maxilla to close the bite. Increased anterior open bite might require greater surgical impaction of the maxilla. Postoperative relapse from previous bite opening could deepen the bite further and prevent the occurrence of anterior open bite after the surgery. Preoperative orthodontic treatment to decompensate Class III open bite could, therefore, exacerbate anterior cross bite, open bite, and protruding lower lip before surgery. However, in the study of Liao et al., ${ }^{[28]}$ at the time of orthodontic debonding, the surgery-first and orthodontics-first groups displayed no significant differences in face convexity, face height, distance of the upper lip and lower lip from the E line, nasolabial angle, overbite, or peer assessment rating score. The two groups displayed similar maxillary stabilities in the horizontal and vertical directions. For mandibular stability, the surgery-first group showed superior movement at Point B and pogonion compared to the orthodontics-first group postoperatively. This superior movement could increase the overbite and reduce the anterior facial height after surgery, thus maintaining greater overbite. The surgery-first and orthodontics-first groups provided similar treatment outcomes in the way of facial esthetics, occlusion, and stability. However, the treatment time was shorter in the surgery-first group (342 days) than in the orthodontics-first group (512 days). ${ }^{[28]}$

Grubb and Evans also described that orthodontic management of the sagittal (anterior-posterior) component of skeletal Class III malocclusion should involve the removal of the dental compensation prior to surgery by retracting the maxillary incisors and protracting the mandibular incisors. ${ }^{[12]}$ The greater increase in negative overjet could provide greater surgical correction in anterior-posterior dimension. Preoperative proclination of lower incisors was confirmed in the orthodontics-first group, as the lower incisors were proclined $4.5^{\circ}$ before surgery. ${ }^{[29]}$ However, the same lower incisors were retroclined $1.9^{\circ}$ after surgery, and further retroclined $4.5^{\circ}$ following the completion of orthodontic treatment. ${ }^{[29]}$ The final outcome of lower incisors (i.e., position and inclination) was not significantly different between the orthodontics-first group and the surgery-first group. With regard to skeletal difference, the horizontal and vertical skeletal parameters before treatment, before surgery, 1 month after surgery, and following completion of orthodontic treatment displayed no significant differences between the surgery-first and orthodontics-first groups. Only the lower incisors in the orthodontics-first group showed a round-tripping tooth movement. The preoperative decompensation of the lower incisors relapsed to a similar inclination as the initial status upon completion of treatment. Therefore, lengthy preoperative orthodontic 
preparation for dental decompensation is unnecessary in Class III surgical orthodontics. ${ }^{[29]}$

Therefore, the long-term outcomes of surgery-first approach provided in transverse, ${ }^{[27]}$ vertical ${ }^{[28]}$ and sagittal ${ }^{[29]}$ dimensions had shown the same or better skeletal and dental stability, as compared to that in orthodontics-first approach. Why do you need to spend 12-18 months of preoperative orthodontic treatment for gaining nothing in final skeletal-dental stability? Certainly, patients would appreciate immediate improvement in facial esthetics and dental function right after the surgery, in addition to RAP frequently observed in postoperative orthodontic treatment.

In 1977, Epker and Fish described that bone turnover or remodeling in the entire bone area receiving operation greatly increases following osseous surgery. ${ }^{[32]}$ This facilitates orthodontic tooth movement. Frost further observed this RAP in long bone in $1989,{ }^{[39,40]}$ and Wilcko et al ${ }^{[33,41]}$ described similar observations in membranous facial bone in 2001 and 2003. The underlying biological mechanism might involve accelerated bone turnover and decreased bone density by way of a transient burst of localized severe bone resorption and remodeling. ${ }^{[39,40]}$ Liou et al.${ }^{[18]}$ hypothesized that the phenomenon of postoperatively accelerated orthodontic tooth movement might be related to increases in osteoclastic activities and metabolic changes in the dentoalveolus caused by the orthognathic surgery. Biomarkers of osteoclastic activity (such as C-terminal telopeptide of type I collagen) and osteoblastic activity (such as serum alkaline phosphatase) could increase 1 week (osteoclastic) and 1 month (osteoblabstic) after surgery, with elevated levels lasting for 3-4 months. Orthognathic surgery might, therefore, trigger 3-4 months of higher bone metabolism postoperatively, which might then induce accelerated orthodontic tooth movement.

\section{Conclusions}

The surgery-first approach offers an alternative to the orthodontics-first approach for correction of maxillofacial deformity. The final outcomes, in the way of facial esthetics, dental occlusion, and stability, are similar when using orthodontics-first and surgery-first approaches. Dental occlusion and facial esthetics can show immediate improvement after surgery when using a surgery-first approach; this almost eliminates the time spent on preoperative orthodontics. The phenomenon of postoperatively accelerated orthodontic tooth movement also reduces the difficulties associated with and the time spent on postoperative orthodontics. Both the surgeon and orthodontist using a surgery-first approach should be experienced and should cooperate closely to achieve predictable and satisfactory outcomes. Orthodontists should be aware of the orthognathic principles and limits in orthodontic movement, and plan postoperative orthodontic treatment to include dental alignment, incisor decompensation, arch coordination, and occlusal interdigitation. The surgeon should be capable of performing designated osteotomy and intermaxillary fixation with occlusion bite plate on malaligned dental arches and providing the stability after skeletal reposition. Further studies, especially prospective cohort studies or randomized controlled trials, are needed to provide additional clinical evidence to support the surgery-first approach.

\section{Acknowledgment}

The authors would like to thank Drs. Eric Jein-Wein Liou, Ellen Wen-Ching Ko, Yu-Fang Liao, and Yu-Chih Wang for sharing their published data on the surgery-first approach. This study was supported by Chang Gung Memorial Hospital (CMRP Grant Numbers 381611, 381631).

\section{REFERENCES}

1. Poulton DR, Ware WH. The American academy of oral roentgenology joins our journal. Oral Surg Oral Med Oral Pathol 1959;12:389-90.

2. Trauner R, Obwegeser H. The surgical correction of mandibular prognathism and retrognathia with consideration of genioplasty. I. Surgical procedures to correct mandibular prognathism and reshaping of the chin. Oral Surg Oral Med Oral Pathol 1957;10:677-89.

3. Obwegeser HL. Surgical correction of small or retrodisplaced maxillae. The "dish-face" deformity. Plast Reconstr Surg 1969;43:351-65.

4. Poulton DR, Taylor RC, Ware WH. Cephalometric x-ray evaluation of the vertical osteotomy correction of mandibular prognathism. Oral Surg Oral Med Oral Pathol 1963;16:807-20.

5. Bell WH, Creekmore TD. Surgical-orthodontic correction of mandibular prognathism. Am J Orthod 1973;63:256-70.

6. Worms FW, Isaacson RJ, Speidel TM. Surgical orthodontic treatment planning: Profile analysis and mandibular surgery. Angle Orthod $1976 ; 46: 1-25$.

7. Vig KD, Ellis E $3^{\text {rd }}$. Diagnosis and treatment planning for the surgical-orthodontic patient. Dent Clin North Am 1990;34:361-84.

8. Proffit WR, Miguel JA. The duration and sequencing of surgical-orthodontic treatment. Int J Adult Orthodon Orthognath Surg 1995;10:35-42.

9. Proffit WR, White RP Jr. Who needs surgical-orthodontic treatment? Int J Adult Orthodon Orthognath Surg 1990;5:81-9.

10. Sabri R. Orthodontic objectives in orthognathic surgery: State of the art today. World J Orthod 2006;7:177-91.

11. Proffit WR, Turvey TA, Phillips C. The hierarchy of stability and predictability in orthognathic surgery with rigid fixation: An update and extension. Head Face Med 2007;3:21.

12. Grubb J, Evans C. Orthodontic management of dentofacial skeletal deformities. Clin Plast Surg 2007;34:403-15.

13. Graber TM, Vanarsdall RL, Vig KW. Orthodontics: Current principles and techniques, $4^{\text {th }}$ ed. St. Louis: Elsevier Mosby; 2005. 16, p. 1213.

14. Proffit WR, Fields HW, Sarver DM. Contemporary orthodontics, $4^{\text {th }}$ ed. St. Louis, Mo.: Mosby Elsevier; 2007. 12, p. 751. 
15. Bell WH, Proffit WR, White RP. Surgical correction of dentofacial deformities. Philadelphia: Saunders; 1980. 5. p. 1-3.

16. Keim RG. Surgery-first orthognathics. J Clin Orthod 2009;43:77-8.

17. Assael LA. The biggest movement: Orthognathic surgery undergoes another paradigm shift. J Oral Maxillofac Surg 2008;66:419-20.

18. Liou EJ, Chen PH, Wang YC, Yu CC, Huang CS, Chen YR. Surgery-first accelerated orthognathic surgery: Postoperative rapid orthodontic tooth movement. J Oral Maxillofac Surg 2011;69:781-5.

19. Liou EJ, Chen PH, Wang YC, Yu CC, Huang CS, Chen YR. Surgery-first accelerated orthognathic surgery: Orthodontic guidelines and setup for model surgery. J Oral Maxillofac Surg 2011;69:771-80.

20. Park SH, Hyon WS, Lee JK, Lee YK. Paradigm shift in orthognathic surgery: Surgery first orthognathic approach and aesthetic two-jaw surgery. J Korean Soc Aesthet Plast Surg 2010;16:5.

21. Lee RT. The benefits of post-surgical orthodontic treatment. Br J Orthod 1994;21:265-74

22. Behrman SJ, Behrman DA. Oral surgeons' considerations in surgical orthodontic treatment. Dent Clin North Am 1988;32:481-507.

23. Villegas C, Uribe F, Sugawara J, Nanda R. Expedited correction of significant dentofacial asymmetry using a "surgery first" approach. J Clin Orthod 2010;44:97-103.

24. Sugawara J, Aymach Z, Nagasaka DH, Kawamura H, Nanda R. "Surgery first" orthognathics to correct a skeletal class II malocclusion with an impinging bite. J Clin Orthod 2010;44:429-38.

25. Nagasaka H, Sugawara J, Kawamura H, Nanda R. "Surgery first" skeletal Class III correction using the Skeletal Anchorage System. J Clin Orthod 2009;43:97-105.

26. Yu CC, Chen PH, Liou EJ, Huang CS, Chen YR. A Surgery-first approach in surgical-orthodontic treatment of mandibular prognathism-a case report. Chang Gung Med J 2009;33:699-705.

27. Wang YC, Ko EW, Huang CS, Chen YR, Takano-Yamamoto T. Comparison of transverse dimensional changes in surgical skeletal Class III patients with and without presurgical orthodontics. J Oral Maxillofac Surg 2010;68:1807-12.

28. Liao YF, Chiu YT, Huang CS, Ko EW, Chen YR. Presurgical orthodontics versus no presurgical orthodontics: Treatment outcome of surgical-orthodontic correction for skeletal class III open bite. Plast Reconstr Surg 2010;126:2074-83.
29. Ko EW, Hsu SS, Hsieh HY, Wang YC, Huang CS, Chen YR. Comparison of progressive cephalometric changes and postsurgical stability of skeletal Class III correction with and without presurgical orthodontic treatment. J Oral Maxillofac Surg 2011;69:1469-77.

30. Baek SH, Ahn HW, Kwon YH, Choi JY. Surgery-first approach in skeletal class III malocclusion treated with 2-jaw surgery: Evaluation of surgical movement and postoperative orthodontic treatment. J Craniofac Surg 2010;21:332-8.

31. Hernández-Alfaro F, Guijarro-Martínez R, Molina-Coral A, Badía-Escriche C. "Surgery first" in bimaxillary orthognathic surgery. J Oral Maxillofac Surg 2011;69:e201-7.

32. Epker BN, Fish L. Surgical-orthodontic correction of open-bite deformity. Am J Orthod 1977;71:278-99.

33. Wilcko WM, Wilcko T, Bouquot JE, Ferguson DJ. Rapid orthodontics with alveolar reshaping: Two case reports of decrowding. Int $\mathrm{J}$ Periodontics Restorative Dent 2001;21:9-19.

34. Sugawara J. Dr. Junji Sugawara on the skeletal anchorage system. Interview by Dr. Larry W. White. J Clin Orthod 1999;33:689-96.

35. Umemori M, Sugawara J, Mitani H, Nagasaka H, Kawamura H Skeletal anchorage system for open-bite correction. Am J Orthod Dentofacial Orthop 1999;115:166-74

36. Ellis E $3^{\text {rd }}$, McNamara JA Jr. Components of adult Class III malocclusion. J Oral Maxillofac Surg 1984;42:295-305.

37. Bailey LT, Proffit WR, White RP, Jr. Trends in surgical treatment of Class III skeletal relationships. Int J Adult Orthodon Orthognath Surg 1995;10:108-18.

38. Sidlauskas A, Svalkauskiene V, Sidlauskas M. Assessment of skeletal and dental pattern of Class II division 1 malocclusion with relevance to clinical practice. Stomatologija 2006;8:3-8.

39. Frost HM. The biology of fracture healing. An overview for clinicians. Part I. Clin Orthop Relat Res 1989;248:283-93.

40. Frost HM. The biology of fracture healing. An overview for clinicians Part II. Clin Orthop Relat Res 1989;248:294-309.

41. Wilcko MT, Wilcko WM, Pulver JJ, Bissada NF, Bouquot JE. Accelerated osteogenic orthodontics technique: A 1-stage surgically facilitated rapid orthodontic technique with alveolar augmentation. J Oral Maxillofac Surg 2009;67:2149-59. 